Board of Governors of the Federal Reserve System

International Finance Discussion Papers

Number 697

February 2001

\title{
FORECAST UNCERTAINTY IN ECONOMIC MODELING
}

Neil R. Ericsson

NOTE: International Finance Discussion Papers are preliminary materials circulated to stimulate discussion and critical comment. References to International Finance Discussion Papers (other than an acknowledgment that the writer has had access to unpublished material) should be cleared with the author or authors. Recent IFDPs are available at www.federalreserve.gov/pubs/ifdp/ on the Web. 


\title{
FORECAST UNCERTAINTY IN ECONOMIC MODELING
}

\author{
Neil R. Ericsson*
}

\begin{abstract}
This paper provides an introduction to forecast uncertainty in empirical economic modeling. Forecast uncertainty is defined, various measures of forecast uncertainty are examined, and some sources and consequences of forecast uncertainty are analyzed. Empirical illustrations with the U.S. trade balance, U.K. inflation and real national income, and the U.S./U.K. exchange rate help clarify the issues involved.
\end{abstract}

Keywords: econometrics, economics, forecasting, models, uncertainty.

JEL classifications: C1, C53.

\footnotetext{
*Chapter 5 in Understanding Economic Forecasts, David F. Hendry and Neil R. Ericsson (eds.), MIT Press, forthcoming. The author is a staff economist in the Division of International Finance, Board of Governors of the Federal Reserve System, Washington, D.C. 20551 U.S.A., and may be reached on the Internet at ericsson@frb.gov. This paper was initially prepared as an invited lecture for Section F (Economics) of the British Association for the Advancement of Science at their annual conference in Sheffield, England, on September 13-17, 1999. The views in this paper are solely the responsibility of the author and should not be interpreted as reflecting the views of the Board of Governors of the Federal Reserve System or of any other person associated with the Federal Reserve System. I am grateful to Julia Campos, Clive Granger, David Hendry, Jaime Marquez, and Hayden Smith for helpful comments and discussion; to Hayden Smith for research assistance; to Jurgen Doornik for providing me with a beta-test copy of GiveWin Version 2.00; and to the Bank of England for permission to reprint the fan chart and density function in Figures 2 and 3. All numerical results were obtained using PcGive Professional Version 9: see Doornik and Hendry (1996). Data and output listings for this paper's empirical results are available from the author and at www.federalreserve.gov/pubs/ifdp/2001/697/default.htm on the WorldWide Web.
} 


\section{Introduction}

This paper considers forecast uncertainty in econometric modeling, analyzing at a general level certain sources of uncertainty present in economic forecasting. Economic forecasts feature prominently in business decision-making, government policy analysis, and economic research. Economic forecasts typically differ from the realized outcomes, with discrepancies between forecasts and outcomes reflecting forecast uncertainty. Depending upon the degree of forecast uncertainty, forecasts may range from being highly informative to being completely useless for the tasks at hand.

Four issues are central to the discussion of forecast uncertainty:

1. what forecast uncertainty is,

2. what it depends upon,

3. how forecast uncertainty might be measured, and

4. how measures of forecast uncertainty might be used in practice.

Measures of forecast uncertainty have numerous uses. For instance, prior to the realization of outcomes, a measure of forecast uncertainty provides an assessment of the "expected" or predicted uncertainty of the forecast errors, helping to qualify the forecasts themselves and to clarify the expected range of likely outcomes. Also, once outcomes are known, the corresponding forecast errors and the anticipated forecast uncertainty can help evaluate the models from which the forecasts were generated.

Section 2 examines what forecast uncertainty is, and it also considers some measures of forecast uncertainty and some possible practical consequences of forecast uncertainty. Section 3 discusses five possible sources of forecast uncertainty, focusing on two in particular: one is associated with future shocks to the economy, and the other arises from estimating the forecast model. Section 3 also highlights how anticipated forecast uncertainty is affected by the choice of variable being forecast, the type of forecast model (whether static or dynamic), the forecast horizon, the information available, and the underlying economic process. To illustrate the various issues associated with forecast uncertainty, this paper draws on several empirical examples, including the Bank of England's inflation forecast, forecasts of the U.S. trade balance, forecasts of the U.S./U.K. exchange rate, and forecasts of U.K. national income.

Some preliminary comments will aid in following the presentation below. This paper presupposes an understanding of "how economists forecast" on the level of the presentation in Hendry (2001). For the most part, the current paper restricts itself to time series models and econometric models as the tools for forecasting itself. Further, these models are assumed to be well-specified. Clements and Hendry (1998), Clements and Hendry (1999), and Ericsson and Marquez (1998) consider some of the generalizations required and implications for situations in which the empirical forecast model is mis-specified and for which that mis-specification is important. Wallis (1999b) inter alia discusses various ways of characterizing forecast uncertainty in 

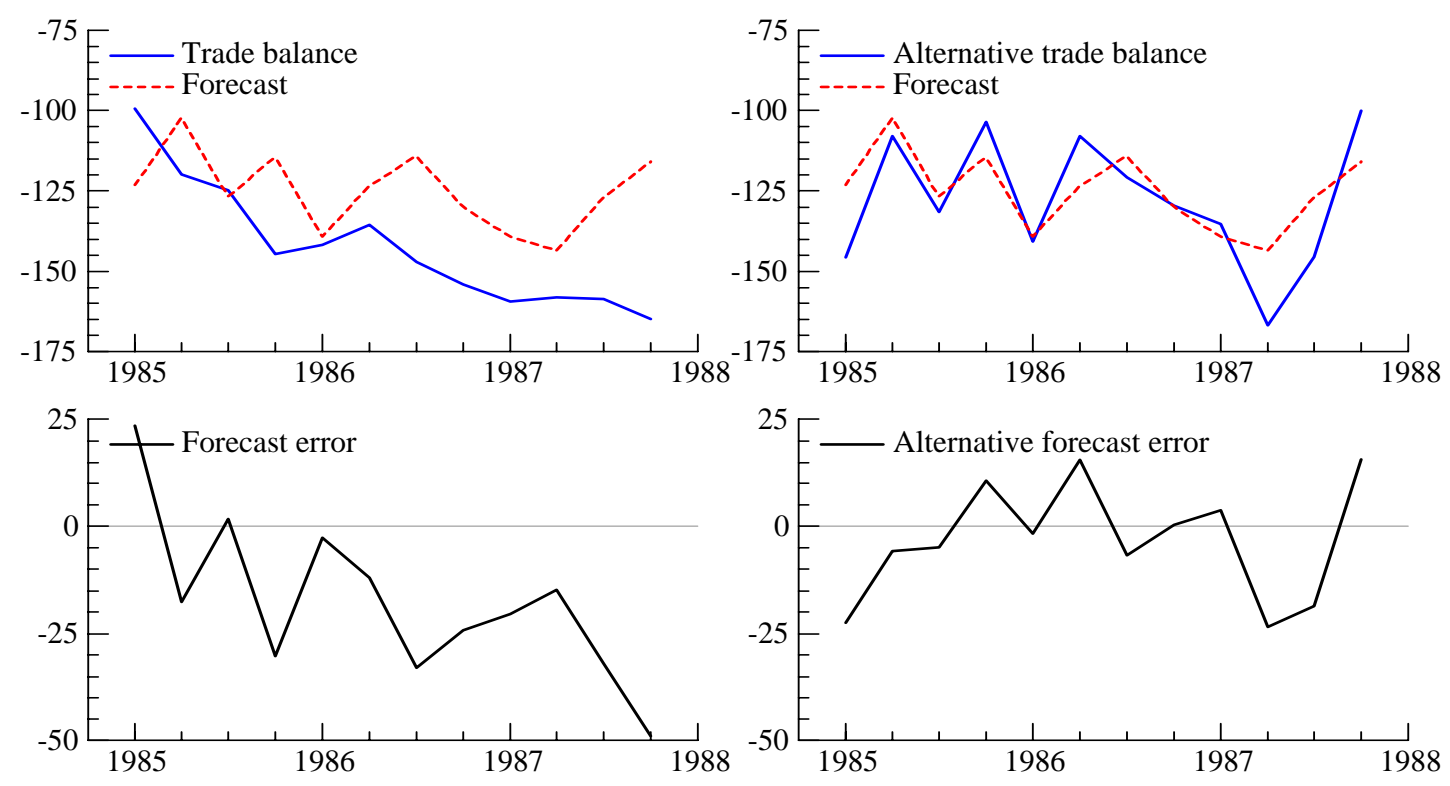

Figure 1: Forecasts, outcomes, and forecast errors of the U.S. trade balance, with alternate outcomes and forecast errors of the trade balance.

macroeconomic modeling. Clements and Hendry (2001) provide extensive summaries on myriad facets of forecasting generally. Finally, and at a very practical level, figures - which are central to the paper's examples - often appear as panels of graphs, with each graph in a panel labeled sequentially by a suffix $a, b, c, \ldots$, row by row.

\section{Forecasts, Outcomes, and Forecast Errors}

This section discusses at an intuitive level what forecast uncertainty is, through examining forecasts, outcomes, and forecast errors. Section 2.1 defines and illustrates what is meant by forecast uncertainty, and Section 2.2 considers various measures of forecast uncertainty and some possible economic consequences of forecast uncertainty. ${ }^{1}$

\subsection{Forecast Uncertainty}

Forecast uncertainty reflects the dispersion of possible outcomes relative to the forecast being made. Figure 1 illustrates this notion through the forecasts and outcomes

\footnotetext{
${ }^{1}$ Strictly speaking, "forecast uncertainty" should be called "forecast error uncertainty" because the forecast error is what is uncertain, not the forecast. However, following common usage in the literature, and for brevity's sake, the phrase "forecast uncertainty" is used throughout this paper.
} 
of the U.S. trade balance, which is the value of exports minus the value of imports. Figure 1a (the upper left graph in the panel) plots the forecasts from a vector autoregressive model (described in Marquez and Ericsson (1993)), along with the outcomes of the trade balance. The forecast errors are simply the outcomes minus the forecasts, and are plotted in Figure 1c, directly below Figure 1a.

These forecast errors are calculated from the observed outcomes for the trade balance. However, the outcomes could have been otherwise. The future trade balance is not known in advance, and it could take a range of values. Figure $1 \mathrm{~b}$ plots an alternate sequence of outcomes for the trade balance, along with the same (original) set of forecasts; and Figure 1d plots the corresponding set of "alternate" forecast errors. Different sequences of outcomes could have occurred, implying different sequences of forecast errors. A whole range of outcomes could arise, some of them being more likely than others. That entails a distribution of forecast errors.

Graphs provide a convenient means for expressing the distribution - and hence the uncertainty - associated with the forecast errors. For example, the Bank of England portrays forecast uncertainty in an ingenious manner through the "fan charts" that it has been publishing recently for its forecasts of both GDP growth and inflation; see the Bank of England (2000, p. iv). Figure 2 reproduces the Bank's fan chart for its November 2000 forecast of RPIX inflation. ${ }^{2}$ The Bank describes this graph as follows.

The fan chart depicting the probability distribution for inflation is rather like a contour map. At any given point during the forecast period, the depth of shading represents the height of the probability density function over a range of outcomes for inflation. The darkest band includes the central (single most likely) projection and covers $10 \%$ of the probability. Each successive pair of bands is drawn to cover a further $10 \%$ of the probability, until $90 \%$ of the probability distribution is covered. The bands widen as the time horizon is extended, indicating increasing uncertainty about outcomes. Bank of England (2000, Chart 2, p. iv)

The fan chart summarizes the Bank's predicted or anticipated probability distribution of inflation outcomes at different forecast horizons.

The Bank of England (2000, Chart 6.4, p. 66) also published the density function corresponding to that distribution at two years out - that density appears in Figure 3. From Figure 3, the Bank's 90\% confidence interval for annual inflation in the twelve months 2002Q1-2002Q4 is from 1\% to 4\% (approximately), as indicated by the shaded

\footnotetext{
${ }^{2}$ RPIX is the U.K. retail prices index for all items, excluding mortgage interest payments. The Bank of England's inflation target is defined in terms of RPIX inflation.

Also, note that, in the Bank of England's graph format, tick marks appear adjacent to the numbers on the right-hand side $y$-axis. In Figure 2, and in Figure 3 below, these numbers are always nonnegative, and the tick marks should not be mis-interpreted as minus signs.
} 


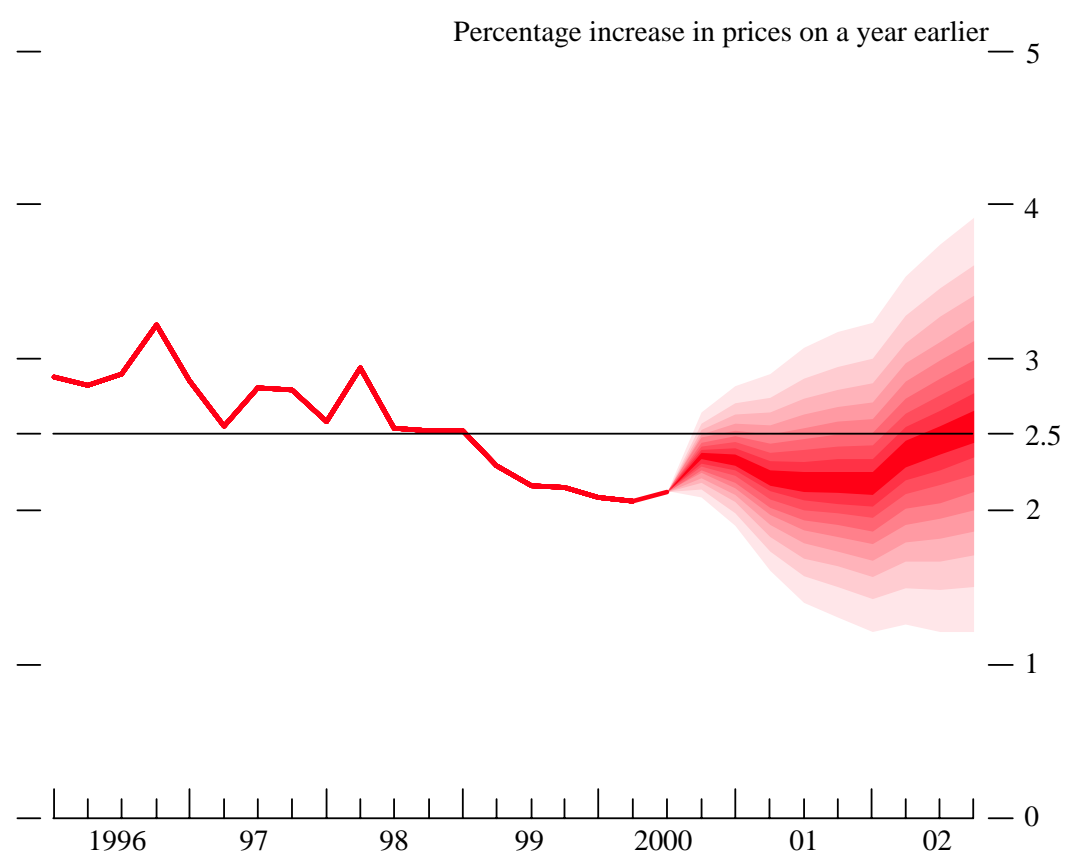

Figure 2: The Bank of England's November 2000 fan chart for projections of RPIX inflation.

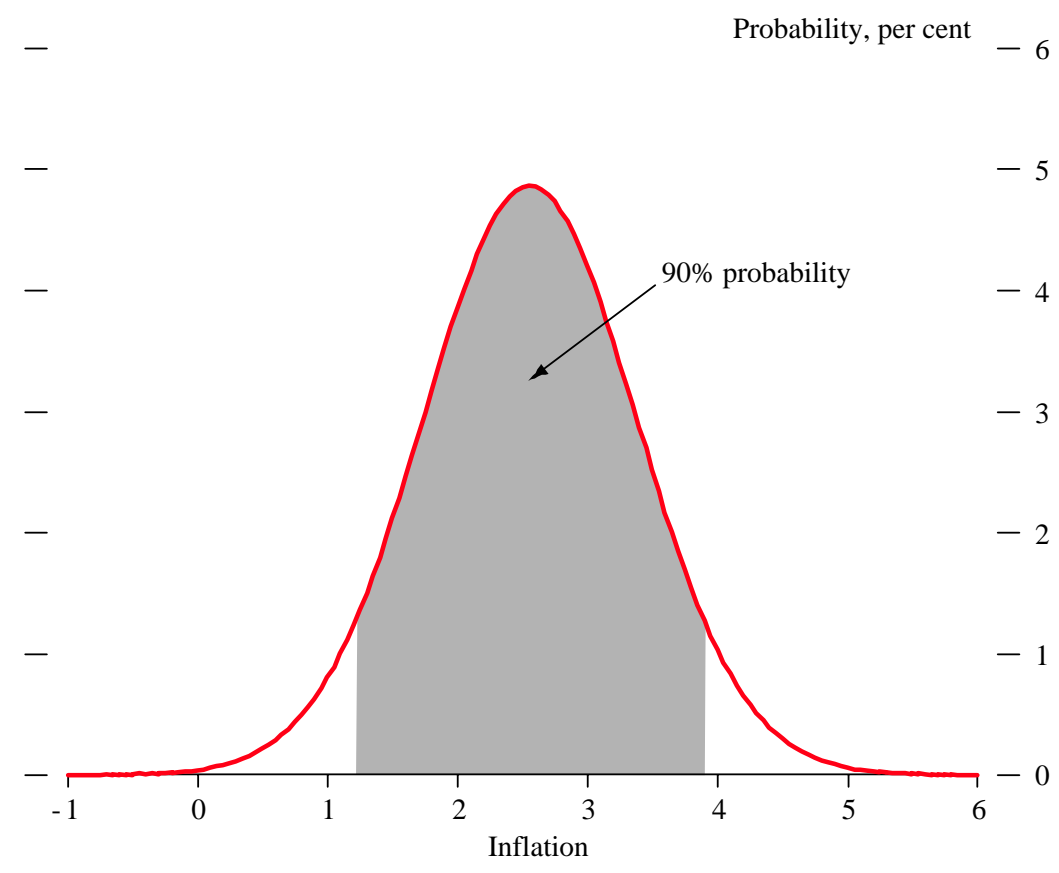

Figure 3: The November 2000 projection by the Bank of England for the probability density of RPIX inflation in the year to 2002Q4. 

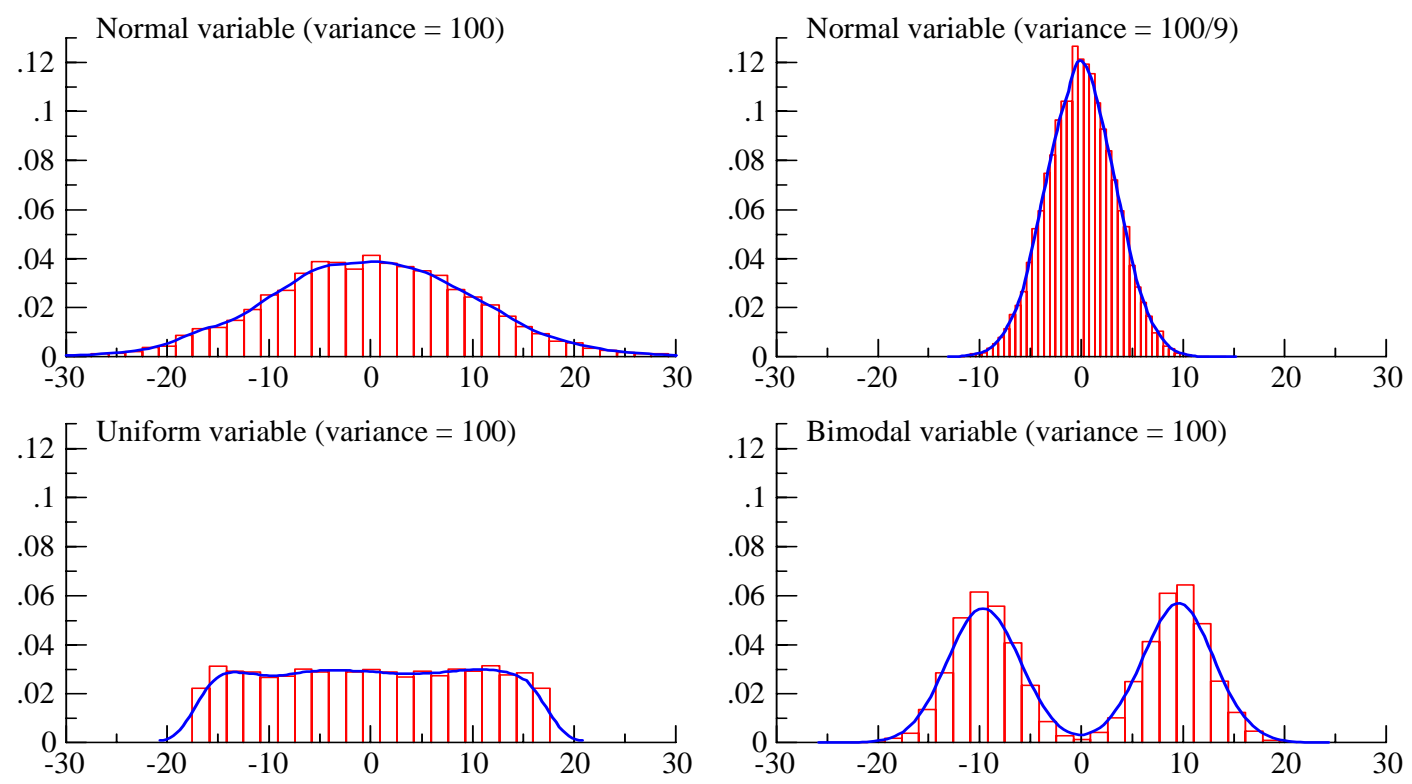

Figure 4: Four examples of possible histograms (displayed as rectangles) and estimated densities (-) for forecast errors.

area in the graph. Other outcomes for inflation could occur outside that range, but the probability of those outcomes is believed to be relatively small. ${ }^{3}$ See Wallis (1999a) and Hatch (2001) for further details on fan charts and forecasting at the Bank of England.

Densities of outcomes are very useful when thinking about forecast errors, as such densities formalize which outcomes are relatively likely and which are relatively unlikely. There are many possible distributions for forecast errors, and the precise nature of those distributions can influence individuals' responses to the corresponding uncertainty. Figure 4 plots four possible densities with corresponding histograms to illustrate two features: the degree of dispersion, typically measured by the variance; and the generic shape of the density. The densities in Figures $4 \mathrm{a}$ and $4 \mathrm{~b}$ have the same shapes - both are Gaussian, or "normal" - but the density in Figure 4a has a variance equal to nine times the variance for the density in Figure $4 \mathrm{~b}$. That is, the density in Figure 4a is much less concentrated around its mean than is the density in Figure 4b, implying that the range of likely outcomes in Figure 4a is much wider than the corresponding range in Figure 4b. Thus, the forecast uncertainty in Figure 4a is

\footnotetext{
${ }^{3}$ The density function in Figure 3 measures the relative frequencies of occurrence for various outcomes of inflation, as expected by the Bank of England from its inflation forecasts. Figure 3 is scaled to deliver the projected probability of inflation within \pm 0.05 percentage points of any given inflation rate. For instance, from Figure 3, the probability of inflation being $2 \%$ per annum (i.e., between $1.95 \%$ and $2.05 \%$ ) is about $4 \%$.
} 
larger than that in Figure $4 \mathrm{~b}$.

The shape of the density can vary, even for a given variance of the forecast errors. Figures 4a, 4c, and 4d all have the same variance - equal to 100 - implying a standard error of 10. However, the densities in those figures have vastly different shapes. Figure 4c is a uniform distribution, with equally likely outcomes between approximately -17 and +17 . Figure $4 d$ illustrates a bimodal density, which here is the combination of two Gaussian densities with means of approximately -10 and +10 each. ${ }^{4}$ The average outcome for each of the four densities in Figures $4 \mathrm{a}-4 \mathrm{~d}$ is zero; but zero is a relatively unlikely outcome in Figure 4d, contrasting with (say) Figures $4 \mathrm{a}$ and 4b. Equally, -10 and +10 are relatively likely outcomes in Figure 4d, but not in Figure 4a, and even less so in Figure 4b. Bimodal densities like the one in Figure 4d may well characterize some economic variables, such as the depreciation rate of some exchange rates, where there might be relatively high probabilities of little depreciation and of large depreciations (e.g., as in an exchange rate crisis), but with a low probability of moderate depreciations. Bimodal densities also may arise when the mean of the variable shifts sometime in the sample being considered, as with a structural break.

\subsection{Measures of Forecast Uncertainty}

Many measures exist for summarizing properties of a forecast and its corresponding forecast error, including the bias of the forecast, the variance of the forecast error, and the mean square forecast error (MSFE), where the last combines the bias and the variance in a statistically appealing manner. In general, the whole distribution of outcomes is of interest when considering forecast uncertainty. That said, the primary measure of forecast uncertainty in economics is the mean square forecast error, which simplifies to the variance of the forecast error when the forecast is unbiased. While Figure 4 highlights some shortcomings to using the variance and MSFE as measures of forecast uncertainty, the variance and MSFE still do capture important aspects of forecast uncertainty and so are considered in much of the discussion below. See Clements and Hendry (1993) for a detailed theoretical analysis of MSFEs and their limitations.

Forecast uncertainty can have many economic consequences. For instance, if the forecast uncertainty in Figure $4 \mathrm{a}$ is viewed as being considerable, insurance might be desirable as a mechanism for protecting against untoward outcomes; and different

\footnotetext{
${ }^{4}$ Figure 4, and also Figures 7 and 8 below, plot histograms and estimated densities for several variables. A histogram is a set of vertical rectangles, with the height of each rectangle representing the variable's frequency of occurrence in the range specified by the rectangle's width. The estimated density is a smoothed interpolation of the histogram. See Doornik and Hendry (1996) for details.

In Figure 4, each histogram and estimated density is of 10,000 Monte Carlo (artificial) random numbers generated to have the distribution specified.
} 
types of insurance might be available. Also, individuals may wish to take advantage of forecast uncertainty. One example is gambling, where forecast uncertainty is inherent to the activity. Likewise, investment by manufacturing firms in machinery and by individuals in the stock market are inherently risky activities, yet those activities are undertaken, with the possibility of large successes being an attraction of such investments. To summarize, forecast uncertainty is ubiquitous in economics, and many consequences may follow from the presence and extent of that uncertainty.

\section{Sources of Forecast Uncertainty}

This section examines the determinants of forecast uncertainty, focusing on two in particular: one is inherent to the uncertainty of future events, and the other depends upon the uncertainty arising from estimating the forecast model itself. Sections 3.1 and 3.2 highlight how the predicted forecast uncertainty is affected by the type of forecast model (whether static or dynamic) and the forecast horizon. Both static and dynamic models have played important roles in forecasting; see Box and Jenkins (1970), Hendry, Pagan, and Sargan (1984), Hendry (1995, Chapter 7), and Clements and Hendry (2000) inter alia. Section 3.3 briefly describes some ways in which measures of forecast uncertainty are used in economics.

Clements and Hendry (1998, Chapter 7.3, especially Table 7.1) develop a five-fold categorization for the sources of model-based forecast error:

1. future changes in the underlying structure of the economy,

2. mis-specification of the model,

3. mis-measurement of the data in the base period from which forecasting begins,

4. inaccuracies in the estimates of model's parameters, and

5. the cumulation of future errors (or "shocks") to the economy.

In practice, all five sources are important when analyzing forecast uncertainty. To paraphrase Maxine Singer (1997, p. 38), the uncertainty from Items 1-3 reflects "what we don't know that we don't know". These sources of uncertainty lie beyond the scope of this paper, but see Hendry (2001). By contrast, Items 4 and 5 are predictable in the sense that the degree of uncertainty arising from them can be anticipated and even calculated. These sources of uncertainty arise from "what we do know that we don't know". This paper focuses on Items 4 and 5 , and primarily on Item 5 .

At a more prosaic level, forecast uncertainty depends upon the variable being forecast, the type of model used for forecasting, the economic process actually determining the variable being forecast, the information available, and the forecast horizon. On the first, some variables may be inherently more difficult to forecast than others. For instance, imports and exports each might be highly predictable, and good models might exist for forecasting them. The trade balance - that is, the value of exports minus imports - might be quite difficult to forecast. Specifically, by being 
the difference between two relatively large quantities (exports and imports), the trade balance is itself a relatively small quantity, whereas its forecast error reflects the forecast errors of both imports and exports. As another example, forecasting the level of the exchange rate might be relatively easy, in that the exchange rate in (say) a month's time is likely to be close to today's exchange rate. That said, forecasting the change in the exchange rate over the next month could be quite difficult. Thus, the particular variables being forecast and the transformations applied to those variables can affect the degree of forecast uncertainty present.

Secondly, forecast uncertainty depends upon the model that is being used for forecasting. Some models may simply be better for forecasting than others. Also, the precise form of the model determines the anticipated forecast uncertainty in light of that model, as distinct from the actual forecast uncertainty that arises. That distinction exists because a model is a simplified characterization of the economy, not a reproduction of the economy. Sometimes that characterization is a good one, and sometimes it is not.

Thirdly, and relatedly, the underlying process generating the data plays a role in determining forecast uncertainty, as by placing limits on the minimum actual forecast uncertainty obtainable from a model. That distinguishes between the predicted forecast uncertainty - that is, the forecast uncertainty that one would anticipate, given the model — and the actual forecast uncertainty, which is the uncertainty arising from the combination of the model with the actual behavior of the economic data.

Fourthly, forecast uncertainty depends upon the information available for constructing the forecasts. This aspect is closely tied to the design of the forecast model. More information would seem to be beneficial for forecasting, and it is so in some situations. That said, when the model is mis-specified and there are structural breaks in the data, use of additional information can actually increase forecast uncertainty; see Clements and Hendry (1999, Chapter 2).

Finally, the forecast horizon can influence the degree of forecast uncertainty, as highlighted in the Bank of England's fan chart.

\subsection{Forecast Uncertainty and Static Models}

To illustrate the notion of forecast uncertainty, this subsection considers two simple cases, one of forecasting a taxi fare, and a second of forecasting real national income for the United Kingdom. In both cases, the models are static.

Consider forecasting the taxi fare for traveling next Monday morning from my home to work. From previous cab rides, I know that the fare is calculated from the miles traveled and the time spent in the cab:

$$
\text { fare }=(\$ 2.00 / \text { mile }) \times(\text { miles traveled })+(\$ 0.10 / \text { minute }) \times(\text { minutes in cab }) \text {. }
$$

The distance traveled is 2 miles, and the time spent in the cab is 10 minutes on 
average. However, the actual time in the cab varies, depending upon traffic, the weather, the aggressiveness of the particular cab driver, and so on - all factors that I don't know currently. These unknown factors contribute to Item 5 above: future shocks. Thus, I might forecast a fare of $\$ 5.00$. Yet, when I actually take the cab, I might have a larger or smaller fare, such as $\$ 5.30$ or $\$ 4.90$. The forecast uncertainty would reflect my anticipated variation in possible lengths of time spent in the cab.

Item 4 contributes to the forecast error through the imprecision in the estimates of the parameters of the model. In the taxicab example, such imprecision could arise from (e.g.) my incorrect recollection that the minute charge was $\$ 0.10 /$ minute, rather than the actual charge of $\$ 0.20 /$ minute, in which case the "estimated" formula above for the fare is inaccurate. Or, I could have an altogether incorrect model for the fare. For instance, the fare might be a flat charge between two regions of town and not depend on the time taken at all. That sort of mis-specification would fall under Item 2 .

Returning to the formula above, my forecast for a typical fare might be $\$ 5.00$, with a certain amount of uncertainty associated with the outcome. Unless (e.g.) some days are known to have heavier or more variable traffic than others, the forecast and the forecast uncertainty are in essence static. My forecast for next Monday's fare is the same as for next Tuesday's fare, and the anticipated distribution of forecast errors for next Monday is the same as for next Tuesday's. That is, the timing of the next cab ride - in terms of the day on which it actually occurs - is unimportant for the forecast and for forecast uncertainty, other than that the ride occurs in the future.

As a second example, consider modeling real net national income in the United Kingdom over 1970-1993 and forecasting it over 1994-2010. The data are from Ericsson, Hendry, and Prestwich (1998), and the model is a very simple one: namely, that real net national income (in logarithms) is equal to an intercept plus a linear trend plus an error. ${ }^{5}$ Algebraically, the model implies the following relation for income in the first forecast period (1994):

$$
\begin{aligned}
\text { income }_{1994} & =\text { intercept }+\left(\text { trend coefficient } \times \text { trend }_{1994}\right)+\text { error }_{1994} \\
& =\text { intercept }+(\text { trend coefficient } \times 1994)+\text { error }_{1994},
\end{aligned}
$$

where a subscript on a variable indicates the dating of the subscripted variable, and where the trend coefficient captures any fixed, systematic shift in income from one period to the next. For this model, the one-year ahead forecast of income is the intercept, plus the trend coefficient times the value of the trend in 1994. As the second line in the equation above indicates, the trend in 1994 equals 1994 itself. The uncertainty associated with the forecast for 1994 reflects the distribution of the error in 1994, i.e., of error ${ }_{1994}$.

\footnotetext{
${ }^{5}$ Even although 1994 is some years in the past, the forecast period begins in 1994 because the date of the most recent observation in Ericsson, Hendry, and Prestwich's (1998) dataset is 1993.
} 

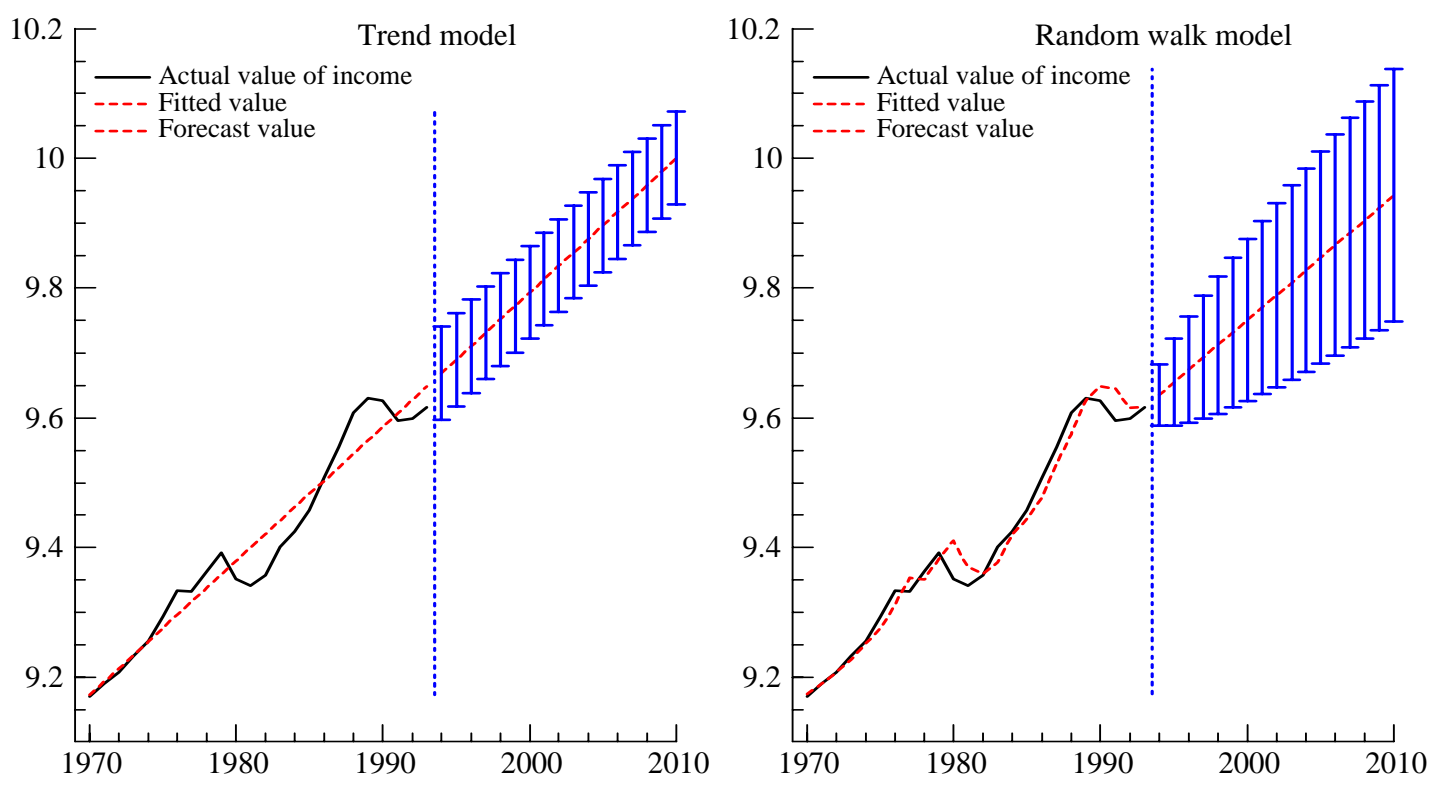

Figure 5: Actual, fitted, and forecast values from the trend and random walk models of annual real net national income for the United Kingdom (in logs), with $95 \%$ confidence intervals for the forecasts.

Consider forecasting two years ahead. The trend model implies that income in 1995 is:

$$
\begin{aligned}
\text { income }_{1995} & =\text { intercept }+\left(\text { trend coefficient } \times \operatorname{trend}_{1995}\right)+\text { error }_{1995} \\
& =\text { intercept }+(\text { trend coefficient } \times 1995)+\text { error }_{1995} .
\end{aligned}
$$

The forecast of income in 1995 is the intercept, plus the trend coefficient times the value of the trend in 1995. The uncertainty associated with this forecast reflects the distribution of the error in 1995 , i.e., of error ${ }_{1995}$. In general, for forecasts multiple periods ahead, the forecast error for the trend model is the model error for the period being forecast. The final period forecast (2010) is 17 periods ahead relative to the last period observed (1993), and the forecast error for 2010 is the model error for 2010, i.e., error $_{2010}$.

For standard trend models, the model errors are assumed to be independent across time and to have the same properties over time, implying that the forecast uncertainty remains constant across different forecast horizons. While the trend itself does vary over time, the trend is deterministic, implying that its future values are known, as well as its current and past values. So, this trend model is in essence static, and the anticipated forecast uncertainty is constant across different forecast horizons.

Figure 5a shows the results from estimating this trend model and forecasting from it. The left half of Figure 5a plots actual income and the fitted values of income 
from the model estimated over 1970-1993. The right half of Figure 5a plots the model's forecasts, which date from 1994 through 2010. The vertical bars around those forecasts represent the anticipated 95\% confidence intervals for income, much as the outer edges of the Bank of England's fan chart represent the Bank's 90\% confidence intervals for inflation. As implied above, these $95 \%$ confidence intervals do not vary over the forecast horizon.

\subsection{Forecast Uncertainty and Dynamic Models}

Drawing on examples involving U.K. national income, the U.S./U.K. exchange rate, and the U.S. trade balance, this subsection shows how dynamics in a model can affect forecast uncertainty. In particular, model dynamics often imply that forecast uncertainty increases with the forecast horizon, where the latter is the length of time from the period in which the forecast is made to the period being forecast. Many economic data series are highly dynamic, in that they are characterized by strong time dependence, persistence, or memory. Visibly, the income series in Figure 5 has strong persistence present, as do many other economic variables, such as exchange rates, interest rates, consumers' expenditure, and inflation. Incorporation of time dependence into a forecast model often implies that forecast uncertainty increases as the forecast horizon lengthens. This feature is exemplified by the Bank of England's fan chart (Figure 2 above): for instance, the forecast uncertainty for 2002Q4 is larger than that for 2001Q1.

Many models imply that forecast uncertainty depends upon the forecast horizon. One model — the random walk model — is especially useful for demonstrating that dependence, as the following illustration with the national income data shows. When applied to income, the random walk model posits that income in a given period equals a constant term or intercept, plus the previous period's income, plus a shock (or error term), where the intercept captures any fixed, systematic shift in income from one period to the next. Algebraically, the model implies the following relation for income in the first period forecast (1994):

$$
\text { income }_{1994}=\text { intercept }+ \text { income }_{1993}+\text { error }_{1994} \text {. }
$$

(The intercept and error in this equation are generally not the same as the intercept and error in the trend model above.) In this random walk model, the forecast of income in 1994 is the intercept plus income in 1993, where the value of income in 1993 is known. The associated forecast uncertainty reflects the distribution of the error in the following year, i.e., of error $_{1994}$.

For forecasting two years ahead, the random walk model implies:

$$
\begin{aligned}
\text { income }_{1995} & =\text { intercept }+ \text { income }_{1994}+\text { error }_{1995} \\
& =(2 \times \text { intercept })+\text { income }_{1993}+\left(\text { error }_{1994}+\text { error }_{1995}\right)
\end{aligned}
$$


where the second line is obtained by substitution. The forecast of income for 1995 is the income in 1993 plus twice the value of the intercept, and this forecast's uncertainty reflects the distribution of the model errors in both 1994 and 1995, combined as error $_{1994}+$ error $_{1995}$. In general, those errors don't cancel; rather, they cumulate.

For forecasts multiple periods ahead, the forecast error from the random walk model is the sum of the model errors over the forecast horizon. So, in this model, the outcomes of future income reflect the cumulation of shocks over time, as might occur from technological innovation. For the final period forecast (2010), the corresponding forecast error is the sum of all model errors from 1994 (the first period forecast) through 2010. That is, the forecast error for 2010 is:

$$
\text { error }_{1994}+\text { error }_{1995}+\cdots+\text { error }_{2009}+\text { error }_{2010} \text {. }
$$

That contrasts with the trend model's forecast error for 2010, which is just error 2010 .

Figure 5b plots the actual, fitted, and forecast values from this random walk model of income, using the same sample periods for estimation and forecasting as with the trend model in Figure 5a. The confidence intervals for the random walk forecasts in Figure 5b increase very substantially as the forecast horizon itself increases, contrasting with confidence intervals of fixed width in Figure 5a for the trend model.

Figures 5a and 5b portray two very different patterns for the anticipated forecast uncertainty, and their comparison illustrates how model choice can affect those patterns. Exactly the same series is being modeled and forecast in Figures 5a and 5b: only the models themselves differ. More generally, static models commonly imply forecast uncertainty that is time invariant or nearly so; whereas dynamic models typically imply time-dependent forecast uncertainty, often increasing in the forecast horizon. The trend and random walk models above present static and dynamic relationships as black and white, but in practice a whole spectrum of models exists with both static and dynamic features.

In order to examine other aspects of forecast uncertainty and to highlight the consequences of dynamics in forecasting, consider another time series, that of the U.S./U.K. exchange rate. Figure 6a plots the level of this series, measured in $\$ / £$, over the period 1971-2000. This exchange rate exhibits very considerable time dependence. The value of the exchange rate in one period is very similar to its value in the previous period - hence the presence of time dependence, or persistence, or memory. Figure $6 \mathrm{~b}$ plots the monthly rate of change in the exchange rate, expressed as a fraction. The time dependence of the rate of change is much less than that of the original series itself, as is typical for many economic variables.

To see the dependence of forecast uncertainty on the forecast horizon in dynamic models, consider the empirical density of the forecast error at different forecast horizons when using a random walk model for forecasting the exchange rate. Specifically, Figure 7 plots the empirical densities of the forecast errors at forecast horizons of 1 month, 3 months, 6 months, 9 months, 12 months, and 24 months. As the forecast 

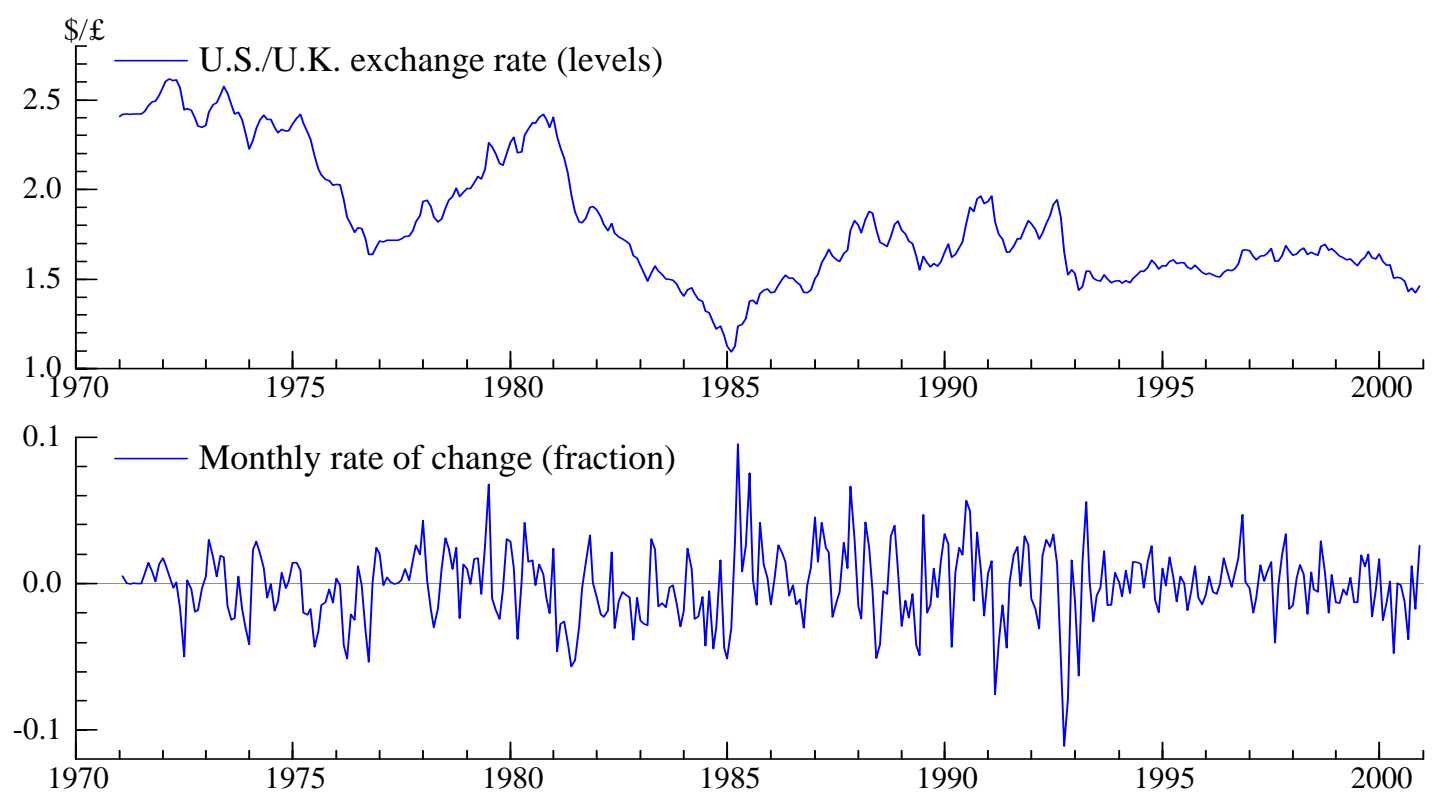

Figure 6: The U.S./U.K. exchange rate, and its monthly rate of change (as a fraction).
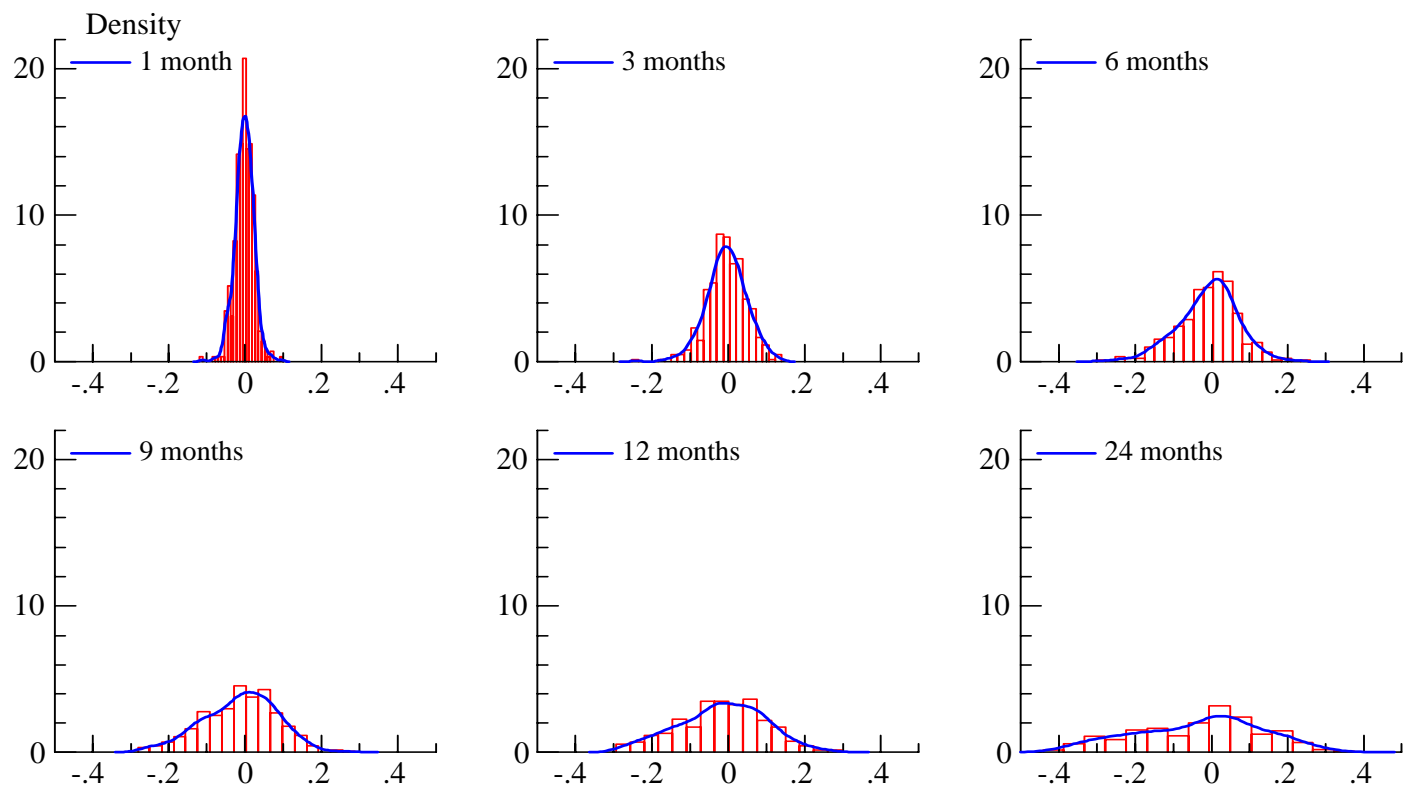

Figure 7: Histograms and estimated densities of forecast errors for the U.S./U.K. exchange rate at 1-, 3-, 6-, 9-, 12-, and 24-month horizons (expressed as a fraction of the exchange rate). 

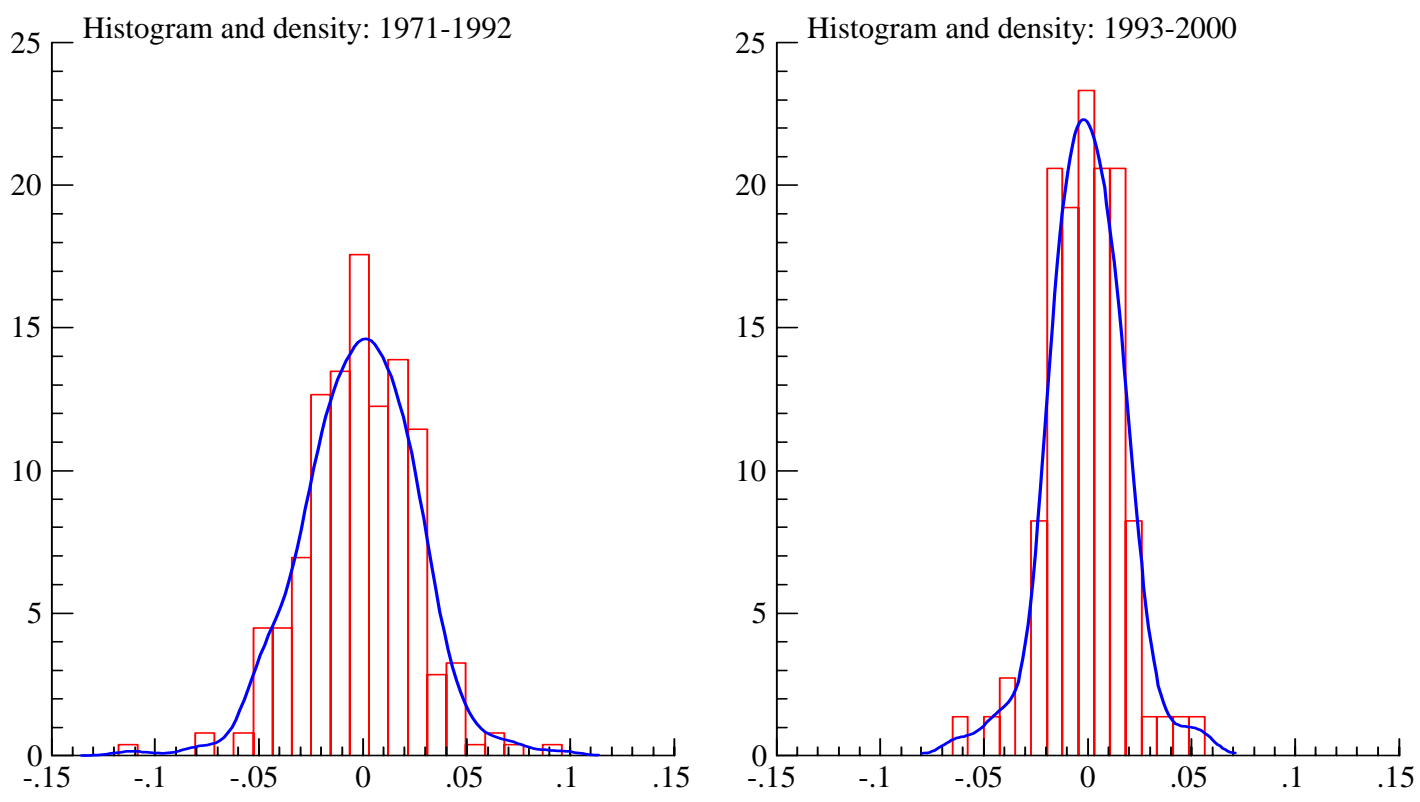

Figure 8: Histograms and estimated densities of one-month ahead forecast errors for the U.S./U.K. exchange rate over two subsamples: 1971-1992 and 1993-2000.

horizon increases, the density becomes flatter and the dispersion of forecast errors becomes larger, reflecting an increased dispersion of outcomes and an increased forecast uncertainty. At only two years out, the uncertainty is considerable: the majority of changes in the exchange rate are in excess of $10 \%$ in absolute value, with some changes being nearly $\pm 50 \%$. Empirically, the forecast uncertainty for the exchange rate depends upon the forecast horizon, with greater uncertainty at longer horizons - certainly an intuitive result.

The plots of the exchange rate and its rate of change in Figure 6 suggest an alteration in exchange rate behavior after the exchange rate crisis in 1992. From 1993 onwards, the exchange rate appears to be much more stable and to have much less volatility than previously. That characterization is also reflected in the empirical densities of the 1-month ahead forecast errors over the respective subsamples, as plotted in Figure 8a (for 1971-1992) and Figure 8b (for 1993-2000). The density of the forecast errors for the more recent period is more concentrated than the one for the period ending in 1992: that is, recent forecast errors have tended to be smaller in absolute value than ones prior to 1993. Empirically, the forecast error variance over 1993-2000 is less than half that over 1971-1992. The change in the distribution of the forecast errors suggests a change in the behavior of the exchange rate, which might require redesign of the forecast model. While such redesign goes beyond the scope of this paper, it is the topic of much current research in economics; see Hendry (1987), 


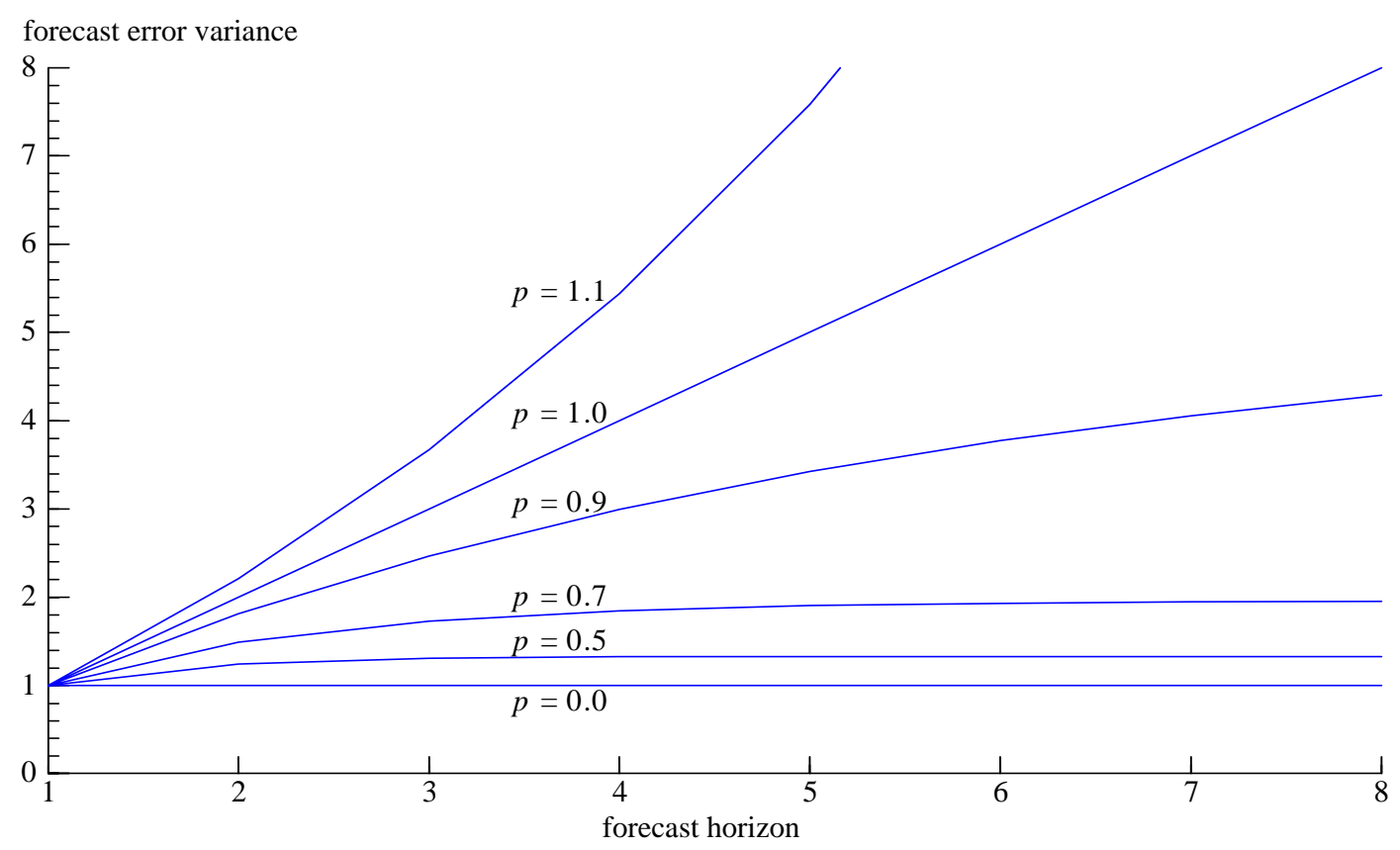

Figure 9: Hypothetical variances of forecast errors, as a function of the degree of persistence $p$ and of the forecast horizon (in periods).

Hendry (1995), Hoover and Perez (1999), and Krolzig and Hendry (2001) inter alia.

The random walk model - examined here for both real national income and the exchange rate - embodies a very striking version of persistence, in which past shocks are felt forever into the future with their full effect. For the random walk model, the variance of the forecast errors increases in proportion to the length of the forecast horizon. More generally, the variance of the forecast errors from a dynamic model depends both on the forecast horizon and on the degree of persistence captured by the model. Suppose that the degree of persistence is quantified by some number " $p$ " ( $p$ for persistence), with unity $(p=1)$ characterizing the strong persistence in a random walk model, and zero $(p=0)$ characterizing the lack of persistence in a static model. Degrees of persistence between zero and unity are possible, and Figure 9 plots how the variance of the forecast errors might depend on both the degree of persistence and the forecast horizon. For models with estimated persistence less than unity, forecast uncertainty typically increases in the forecast horizon but asymptotes to some finite value, rather than increasing without bound, as it does for the random walk model. ${ }^{6}$

Finally, consider a comparison across 1-period and multiple-period ahead forecasts from both static and dynamic models. Marquez and Ericsson (1993) analyze in detail the forecasts from various models of the U.S. trade balance, and this subsection now

\footnotetext{
${ }^{6}$ The results in Figure 9 are normalized such that the one-period ahead forecast error variance is the same for all values of $p$ and equals unity.
} 

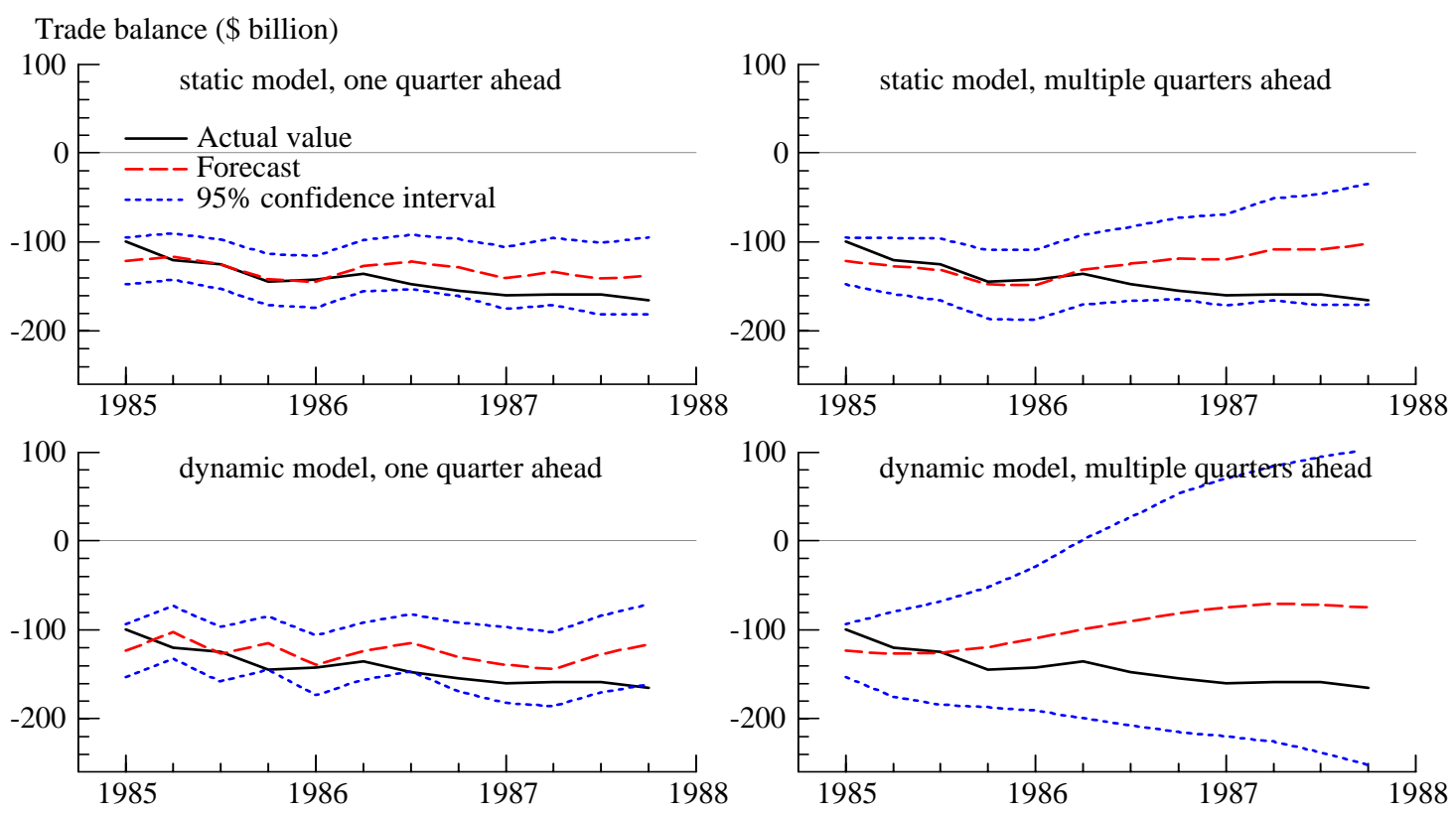

Figure 10: Actual (-) and forecast (- - ) values from two models of the real U.S. trade balance, both one quarter and multiple quarters ahead, with 95\% confidence intervals (- - ) for the forecasts.

examines forecasts from two of Marquez and Ericsson's models. The first model is essentially a static model, and the second model is a highly dynamic model. (In the notation of Marquez and Ericsson (1993), these are Models M1 and M5.) Figure 10 plots the forecasts, actual outcomes, and $95 \%$ forecast confidence intervals for each of these two models, both one quarter ahead and for multiple quarters ahead. For the near-static model, the width of the confidence interval varies only slightly with

the forecast horizon. For the dynamic model, the width of the multi-period ahead confidence interval is highly dependent upon the forecast horizon, with much larger forecast uncertainty at longer horizons. These multi-period ahead confidence intervals are very similar in character to those in the Bank of England's fan chart. The fan shape of the confidence intervals in both instances suggests the very dynamic nature of the variable being forecast and of the implied model being used to forecast it.

\subsection{Measures of Forecast Uncertainty in Practice}

Measures of forecast uncertainty have numerous uses in economic practice. Firstly, prior to the realization of outcomes, a measure of forecast uncertainty provides an assessment of "expected" or predicted uncertainty of the forecast errors, helping to qualify the forecasts themselves and to give a picture of the expected range of likely 
outcomes. That is, information about forecast uncertainty is important in addition to the forecast itself. See Campos (1992), Barrell (2001), Hatch (2001), Hendry (2001), and Osborn, Sensier, and Simpson (2001) inter alia for empirical applications that include measures of forecast uncertainty.

Secondly, forecasts, outcomes, the corresponding forecast errors, and the anticipated forecast uncertainty can help evaluate the models from which the forecasts were generated. For instance, if the forecast errors lie well outside the range that was anticipated, that indicates specification problems with the model. Such evaluation has been central to testing and improving empirical economic models. See Chow (1960) for the initial development of these evaluation techniques; Chong and Hendry (1986), Ericsson (1992), Hansen (1992a, 1992b), Andrews (1993), and West (1996) for more recent contributions; Granger (2001) for an overview; Goldfeld (1973, 1976), Judd and Scadding (1982), and Baba, Hendry, and Starr (1992) for examples in modeling the demand for money; and Marquez and Ericsson (1993) and Ericsson and Marquez (1993) for analysis of the U.S. trade balance forecasts described above. In the future, economists could likewise examine whether the Bank of England's published confidence bands reflect what happened in the data or if those bands were too narrow or too wide. Such an analysis could benefit the construction of future monetary policy. Assessment of model forecasts is also central to evaluating the Lucas (1976) critique, with corresponding model constancy tests providing the primary empirical basis for confirming or refuting the Lucas critique; see Hendry (1988), Engle and Hendry (1993), and Ericsson and Irons (1995).

Predicted forecast uncertainty thus permits assessing how important Items 1-3 (in the forecast error taxonomy) are in contributing to the realized forecast error. Specifically, Items 1-3 reflect discrepancies between the model used for forecasting and the actual behavior of the economy, with Item 1 being primarily responsible for forecast failure in econometric models. Changes in government economic policy may contribute to Item 1, as illustrated by the various policy simulations in Turner (2001). While the current paper ignores Items 1-3 for expository convenience, they can be very important in practice.

Thirdly, and relatedly, the degree of forecast uncertainty present depends in fair part on the information available when forecasting. Forecast uncertainty may decline if the information available for forecasting is increased and if that information affects the variables being forecast in a systematic fashion. Efforts to improve the models being used for forecasting may help reduce the implied forecast uncertainty.

Fourthly, a measure of forecast uncertainty helps distinguish between numerical accuracy and statistical accuracy in forecasts. A forecast might be numerically inaccurate, but statistically accurate. For instance, the forecast might deviate considerably numerically from actual outcomes, as in Figure 10d, where some of the forecast errors of the U.S. trade balance are of the order of $\$ 80$ billion, a considerable sum. Statistically, those forecast errors are well within the range anticipated from the forecast 
uncertainty associated with the model generating those forecasts. Conversely, forecast errors might be numerically small, but still be detectable statistically as lying outside the range of anticipated forecast uncertainty. Expressed slightly differently, a distinction exists between poor forecasts - ones that have associated numerically large forecast errors - and forecast failure, in which the forecast errors are larger than anticipated, given the forecast uncertainty associated with the forecast model.

Finally, many real-life implications follow from the degree of forecast uncertainty present. We, as individuals, make plans for the future; and what actually happens in the future affects us through those plans relative to the actual outcomes. We may thus adjust our behavior in the face of forecast uncertainty. Sometimes we may wish to protect ourselves against a range of outcomes, as by taking out insurance. For instance, we might prepay major expenses of a holiday abroad in order to avoid exchange rate risk. Likewise, importers of goods might engage in forward contracts to protect themselves from exchange rate risk. We may also wish to accept some uncertainty in order to take advantage of the range of potential outcomes available, as in participating in stock markets. Governments may consider the implications of forecast uncertainty and, in particular, the consequences of and costs to making forecast errors in economic policy; see Burns (2001) and Coyle (2001).

\section{Conclusions}

Forecast uncertainty reflects the dispersion of possible outcomes relative to the forecast being made. Numerous measures of forecast uncertainty are available, with the variance of the forecast errors and the mean square forecast error being commonly used in practice. The entire distribution of potential outcomes may be of interest, and not just a summary measure; and graphs can aid in conveying the properties of that distribution. While this paper has illustrated these issues with some simple

models, the issues themselves are generic to forecasting; see Clements and Hendry (2001). Actual forecast models may involve both static and dynamic components, they may be mis-specified, and the forecasts themselves may be of sets of variables rather than of individual variables.

Forecast uncertainty arises both from "what we don't know that we don't know" and from "what we do know that we don't know". In econometric models, forecast uncertainty from the latter can be calculated numerically. Forecast uncertainty also depends upon the variable being forecast, the type of model used for forecasting, the economic process actually determining the variable being forecast, the information available, and the forecast horizon.

Forecast uncertainty appears intrinsic to the world in which we live, and an awareness of that uncertainty helps improve our understanding of forecasts themselves, as with the Bank of England's fan charts. Measures of forecast uncertainty also provide 
economists with a way of assessing the importance of unmodeled features of the economy, both directly through the calculated forecast uncertainty, and indirectly through comparison of that calculated uncertainty with the realized distribution of forecast errors.

\section{References}

Andrews, D. W. K. (1993) "Tests for Parameter Instability and Structural Change With Unknown Change Point", Econometrica, 61, 4, 821-856.

Baba, Y., D. F. Hendry, and R. M. Starr (1992) "The Demand for M1 in the U.S.A., 1960-1988", Review of Economic Studies, 59, 1, 25-61.

Bank of England (2000) Inflation Report: November 2000, Bank of England, London.

Barrell, R. (2001) "Forecasting the World Economy in an Uncertain Environment", Chapter 9 in D. F. Hendry and N. R. Ericsson (eds.) Understanding Economic Forecasts, MIT Press, Cambridge, Massachusetts, forthcoming.

Box, G. E. P., and G. M. Jenkins (1970) Time Series Analysis: Forecasting and Control, Holden-Day, San Francisco.

Burns, T. (2001) "The Costs of Forecasting Errors", Chapter 10 in D. F. Hendry and N. R. Ericsson (eds.) Understanding Economic Forecasts, MIT Press, Cambridge, Massachusetts, forthcoming.

Campos, J. (1992) "Confidence Intervals for Linear Combinations of Forecasts from Dynamic Econometric Models", Journal of Policy Modeling, 14, 4, 535-560.

Chong, Y. Y., and D. F. Hendry (1986) "Econometric Evaluation of Linear Macroeconomic Models", Review of Economic Studies, 53, 4, 671-690.

Chow, G. C. (1960) "Tests of Equality Between Sets of Coefficients in Two Linear Regressions", Econometrica, 28, 3, 591-605.

Clements, M. P., and D. F. Hendry (1993) "On the Limitations of Comparing Mean Square Forecast Errors", Journal of Forecasting, 12, 8, 617-637 (with discussion and reply).

Clements, M. P., and D. F. Hendry (1998) Forecasting Economic Time Series, Cambridge University Press, Cambridge, England.

Clements, M. P., and D. F. Hendry (1999) Forecasting Non-stationary Economic Time Series, MIT Press, Cambridge, Massachusetts. 
Clements, M. P., and D. F. Hendry (2000) "Forecasting with Difference-stationary and Trend-stationary Models", Econometrics Journal, 4, 1, S1-S19.

Clements, M. P., and D. F. Hendry (eds.) (2001) Companion to Economic Forecasting, Blackwell Publishers, Oxford (forthcoming).

Coyle, D. (2001) "Making Sense of Published Economic Forecasts", Chapter 4 in D. F. Hendry and N. R. Ericsson (eds.) Understanding Economic Forecasts, MIT Press, Cambridge, Massachusetts, forthcoming.

Doornik, J. A., and D. F. Hendry (1996) PcGive Professional 9.0 for Windows, International Thomson Business Press, London.

Engle, R. F., and D. F. Hendry (1993) "Testing Super Exogeneity and Invariance in Regression Models", Journal of Econometrics, 56, 1/2, 119-139.

Ericsson, N. R. (1992) "Parameter Constancy, Mean Square Forecast Errors, and Measuring Forecast Performance: An Exposition, Extensions, and Illustration", Journal of Policy Modeling, 14, 4, 465-495.

Ericsson, N. R., D. F. Hendry, and K. M. Prestwich (1998) "The Demand for Broad Money in the United Kingdom, 1878-1993", Scandinavian Journal of Economics, 100, 1, 289-324 (with discussion).

Ericsson, N. R., and J. S. Irons (1995) "The Lucas Critique in Practice: Theory Without Measurement", Chapter 8 in K. D. Hoover (ed.) Macroeconometrics: Developments, Tensions, and Prospects, Kluwer Academic Publishers, Boston, Massachusetts, 263-312 (with discussion).

Ericsson, N. R., and J. Marquez (1993) "Encompassing the Forecasts of U.S. Trade Balance Models", Review of Economics and Statistics, 75, 1, 19-31.

Ericsson, N. R., and J. Marquez (1998) "A Framework for Economic Forecasting", Econometrics Journal, 1, 1, C228-C266.

Goldfeld, S. M. (1973) "The Demand for Money Revisited", Brookings Papers on Economic Activity, 1973, 3, 577-638 (with discussion).

Goldfeld, S. M. (1976) "The Case of the Missing Money", Brookings Papers on Economic Activity, 1976, 3, 683-730 (with discussion).

Granger, C. W. J. (2001) "Evaluation of Forecasts", Chapter 6 in D. F. Hendry and N. R. Ericsson (eds.) Understanding Economic Forecasts, MIT Press, Cambridge, Massachusetts, forthcoming.

Hansen, B. E. (1992a) "Testing for Parameter Instability in Linear Models", Journal of Policy Modeling, 14, 4, 517-533.

Hansen, B. E. (1992b) "Tests for Parameter Instability in Regressions with I(1) Processes", Journal of Business and Economic Statistics, 10, 3, 321-335. 
Hatch, N. (2001) "Modeling and Forecasting at the Bank of England", Chapter 8 in D. F. Hendry and N. R. Ericsson (eds.) Understanding Economic Forecasts, MIT Press, Cambridge, Massachusetts, forthcoming.

Hendry, D. F. (1987) "Econometric Methodology: A Personal Perspective", Chapter 10 in T. F. Bewley (ed.) Advances in Econometrics: Fifth World Congress, Volume 2, Cambridge University Press, Cambridge, England, 29-48.

Hendry, D. F. (1988) "The Encompassing Implications of Feedback versus Feedforward Mechanisms in Econometrics", Oxford Economic Papers, 40, 1, 132-149.

Hendry, D. F. (1995) Dynamic Econometrics, Oxford University Press, Oxford.

Hendry, D. F. (2001) "How Economists Forecast", Chapter 2 in D. F. Hendry and N. R. Ericsson (eds.) Understanding Economic Forecasts, MIT Press, Cambridge, Massachusetts, forthcoming.

Hendry, D. F., A. Pagan, and J. D. Sargan (1984) "Dynamic Specification", Chapter 18 in Z. Griliches and M. D. Intriligator (eds.) Handbook of Econometrics, Volume 2, North-Holland, Amsterdam, 1023-1100.

Hoover, K. D., and S. J. Perez (1999) "Data Mining Reconsidered: Encompassing and the General-to-specific Approach to Specification Search", Econometrics Journal, 2, 2, 167-191 (with discussion).

Judd, J. P., and J. L. Scadding (1982) "The Search for a Stable Money Demand Function: A Survey of the Post-1973 Literature", Journal of Economic Literature, $20,3,993-1023$.

Krolzig, H.-M., and D. F. Hendry (2001) "Computer Automation of General-tospecific Model Selection Procedures", Journal of Economic Dynamics and Control, $25,6-7,831-866$.

Lucas, Jr., R. E. (1976) "Econometric Policy Evaluation: A Critique", in K. Brunner and A. H. Meltzer (eds.) The Phillips Curve and Labor Markets, North-Holland, Amsterdam, Carnegie-Rochester Conference Series on Public Policy, Volume 1, Journal of Monetary Economics, Supplement, 19-46 (with discussion).

Marquez, J., and N. R. Ericsson (1993) "Evaluating Forecasts of the U.S. Trade Balance", Chapter 14 in R. C. Bryant, P. Hooper, and C. L. Mann (eds.) Evaluating Policy Regimes: New Research in Empirical Macroeconomics, Brookings Institution, Washington, D.C., 671-732.

Osborn, D. R., M. Sensier, and P. W. Simpson (2001) "Forecasting and the UK Business Cycle", Chapter 7 in D. F. Hendry and N. R. Ericsson (eds.) Understanding Economic Forecasts, MIT Press, Cambridge, Massachusetts, forthcoming.

Singer, M. (1997) "Thoughts of a Nonmillenarian", Bulletin of the American Academy of Arts and Sciences, 51, 2, 36-51. 
Turner, P. (2001) "Economic Modeling for Fun and Profit: The Role of Economic Models in Generating Economic Forecasts", Chapter 3 in D. F. Hendry and N. R. Ericsson (eds.) Understanding Economic Forecasts, MIT Press, Cambridge, Massachusetts, forthcoming.

Wallis, K. F. (1999a) "Asymmetric Density Forecasts of Inflation and the Bank of England's Fan Chart", National Institute Economic Review, 167, January, 106112.

Wallis, K. F. (1999b) "Macroeconometric Modelling", mimeo, Department of Economics, University of Warwick, Coventry, England, August (presented at a conference at the University of Iceland, Reykjavik, Iceland, May 28-29, 1999).

West, K. D. (1996) "Asymptotic Inference About Predictive Ability", Econometrica, 64, 5, 1067-1084. 